\title{
Myotonic Cataract
}

National Cancer Institute

\section{Source}

National Cancer Institute. Myotonic Cataract. NCI Thesaurus. Code C34833.

A cataract occurring as a sequela of myotonic dystrophy. 